\title{
Towards a model of services based on co-creation, abstraction and restriction
}

Maria Bergholtz , Paul Johannesson, and Birger Andersson

\author{
Department of Computer and Systems Sciences, Stockholm University, Isafjordsgatan 39. \\ SE 16440 Kista, Sweden \\ \{maria, pajo,ba\}@dsv.su.se
}

\begin{abstract}
The term service is today defined and used in a multitude of ways, and there is no usage characteristic that is common for all of these ways. As a consequence natural language terms used for describing services are ambiguous and often confusing. The lack of a common agreed upon definition of the term makes it difficult to understand and classify services as well as distinguish them from non-service concepts. In this paper, we do not propose a new definition of service but a model of services that helps in analysing the concept. The model is based on three perspectives: service as a means for co-creation of value, service as a means for abstraction, and service as a means for providing restricted access to resources.
\end{abstract}

Keywords: service, service model, service definition, service resource, service process, service delivery, Resource-Event-Agent ontology, Hohfeld's classification of Rights, conceptual modeling.

\section{Introduction}

The increasing interest in services has created a multitude of alternative views and definitions, often conflicting, of the service concept. The lack of a common view of the service concept makes it difficult to reason about, describe and classify services in a uniform way.

One attempt to defining services has focused on identifying properties (such as intangibility, inseparability, heterogeneity, and perishability [20]) that distinguish them from other kinds of recourses. However, [3, 4, 16, 5] and others have argued that the suggested properties are neither necessary nor sufficient for something to be a service. For example, not only services are intangible but also other kinds of resources, such as information and IPRs. Heterogeneity can be observed also in the production of certain goods and information, such as handicraft objects and newspaper articles.

An alternative way of identifying services is to view them as perspectives on the use and offering of resources [3]. This view is shared by the Unified Services Theory [16], which also bases its definition of services on the use and exchange of resources; here service processes are processes where customers always provide significant input resources, as opposed to non-service processes where customers only select what output resources to buy and pay for. 
Services may also be understood as a means for abstraction. A common view found in $[18,13,14,10,17]$ is services as an abstraction of activities that once started will achieve some user goal, usually defined as a change of state in (user) resources.

An often mentioned advantage of services is that the management (infrastructure, maintenance, technology, etc.) of resources are moved from customer to provider [12]. This is a consequence of the principle that service provision does not entail ownership transfer [12], [20]. The concept of service can be used as a means for providing restricted resource access without ownership transfer [2].

The diversity of service views and definitions, and the fact that these views are often conflicting, suggest that a multi perspective approach is required. We will introduce a number of service perspectives rather than propose a single service definition. We identify three main service perspectives from the literature introduced in the previous paragraphs: service as a means for co-creation of value $[16,10]$, service as a means for abstraction [18, 13, 14, 10,17], and service as a means for providing resource access without ownership transfer [20, 2]. The purpose of the paper is to propose a conceptual model of services based on these three perspectives. The model has its theoretical foundation in the REA ontology [11] and Hohfeld's classification of rights, [8]. REA is used because it is a well established ontology of business collaboration with the basic view that resources are exchanged between agents according to agreements. Hohfeld's classification of rights is used as means for analysing what kinds of rights are transferred in exchanges of services and other kinds

of resources. The work reported here builds on the work of [2], which is also based on a multi perspective view of analysing services. The main differences are (i): a new foundation for the model based on distinguishing between service as a resource and service as a process, (ii) the alignment of the model concepts with the core REA ontology.

The remainder of this paper is structured as follows. In Section 2, we briefly outline the REA ontology and Hohfeld's classification of rights. In Section 3, we introduce the three perspectives of services and elaborate them together with their corresponding conceptual models in Sections 4 - 6. Section 7 concludes the paper.

\section{The REA Ontology and Hohfeld's Classification of Rights}

The REA (Resource-Event-Agent) ontology was originally formulated in [11] and developed further in a series of papers, e.g. [7, 9]. The ontology is based on the core concepts of resources, events, and agents, which are described in the following subsections.

\subsection{Resources}

A resource is something that is of value for at least one agent, e.g., a car or Internet access. Based on the degree to which a resource is tied to an agent, resources can be classified into three categories: internal resources that are existent dependent on one agent, for example skills, knowledge and experiences, shared resources that are existence dependent on two or more agents, for example relationships and rights, and 
independent resources that can exist independently of any agent, for example land and information.

\subsection{Conversion Processes}

Resources are not unchanging but can be transformed, i.e. they can be produced, modified, used, or consumed. Resources are transformed in so called conversion processes consisting of conversion events. A conversion event represents a transformation of a single resource. A conversion event that creates a new resource or increases the value of an existing resource is called a production event. A conversion event that consumes a resource or decreases the value of a resource without consuming it, is called a consumption event or a usage event, respectively. Usage events are using resources that may be reused in several conversion events, (similar to the concept of 'assets' [6]), while consumption events use up resources (similar to the concept of 'consumables' [6]). Examples of conversion events are the production of bread, the repair of a car, and the consumption of a liter of fuel.

A conversion process is a set of conversion events including at least one production event and at least one consumption or usage event. The latter requirement expresses a duality relationship between production and consumption/usage events, stating that in order to produce or improve some resource, other resources have to be used or consumed in the process. For example, in order to produce a car, a number of other resources have to be used, such as steel, knowledge, and labour.

\subsection{Exchange processes}

Resources can also be exchanged between agents, which occur in exchange processes consisting of exchange events. An exchange event is the transfer of rights on some resource to or from an agent. If the exchange event means that the agent receives rights on a resource, we call the event a take event. If the exchange event means that the agent gives up rights on a resource, we call the event a give event.

An exchange process is a set of exchange events including at least one give event and one take event. Similarly to conversion processes, this requirement expresses a duality relationship between take and give events - in order to receive a resource, an agent has to give up some other resource. For example, in a purchase (an exchange process) a buying agent has to provide money to receive some goods. Two exchange events take place in this process: one where the amount of money is decreased (a give event) and another where the amount of goods is increased (a take event).

\subsection{Hohfeld's Classification of Rights}

In the sections above, we have used the notion of rights in an informal way. As a more precise understanding of rights will be required for characterizing different kinds of resources and exchanges, we here introduce a rights classification based on the work of W. N. Hohfeld, [8], who identified four broad categories of rights: claims, privileges, powers, and immunities (not used in this paper). 
- One agent has a claim on another agent if the second agent is required to act in a certain way for the benefit of the first agent, typically by carrying out some action. Conversely, the second agent is said to have a duty, or an obligation, to the first agent. An example is a person who has a claim on another person to pay an amount of money, implying that the other person has a duty to pay the amount.

- An agent has a privilege on an action if she is free to carry out that action without any interference from the environment in which the action is to be carried out. By environments is here meant social structures such as states, organizations or even families. Some examples of privileges are free speech and the fact that a person owning some property has privileges to use it in various ways.

- A power is the ability of an agent to create or modify a relationship. An example is that a person owning a piece of land has the power to sell it to someone else, thereby creating a new ownership relationship for that piece of land.

Most relationships are governed by a combination of several of these rights. For example, owning a car means to have privileges on using it and also the power to lend or sell it, i.e. creating new ownerships involving other agents.

\subsection{Offerings, Commitments, and Contracts}

Exchange processes can be governed by agreements that specify when and how resources are to be exchanged. The two most important types of agreements are offerings and contracts consisting of commitments. A commitment on a resource type is a duty for an agent to carry out a conversion or exchange event for an instance of that resource type. For example, an agent may have a duty towards another agent to transfer the ownership (an exchange event) of a car (instance of a car type) to that agent. A contract is a collection of commitments and possibly additional rules governing their interrelationships.

An offering for a resource type is a conditional obligation for one agent to some community of agents to enter into a commitment for that resource type. For example, an agent may provide a sales-offering for a certain car model, meaning that she is prepared to sell cars of that model, i.e. enter into commitments for the car model. An offering is similar to a commitment but differs from it by not being binding until another agent has accepted it. Thus, when an offering is accepted, it will result in a commitment. A set of offerings can be collected into a bundled offering, analogously to a contract.

Fig. 1 summarises the notions introduced so far in the form of a UML class diagram. In the following sections, we will suggest further analysis and specialisations of these notions in order to clarify the different perspectives on services. Almost all of the concepts in the conceptual model presented here may exist on both a knowledge level and an operational level. According to [6], the operational level models concrete, tangible individuals in a domain, while the knowledge level models information structures that characterize categories of individuals on the operational level. The diagrams of figure 1 through 5 hence distinguish between knowledge level concepts such as Resource Types (categories of Resources such as Car model, Agent type, Real Estate) and operational level concepts such as Resources (specific and often tangible concepts like a specific car or a concrete piece of land), 
Event Types and Events, and so forth for every concept in the model. Due to space limitations, we include both knowledge and operational level concepts in the diagrams only when both concepts are required to illustrate a focal point in the model.

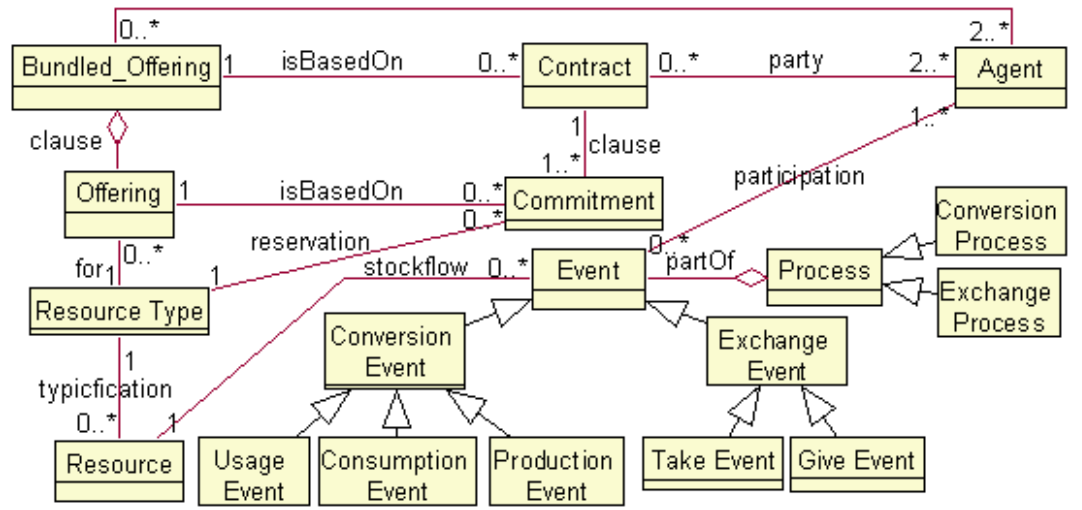

Fig. 1. REA ontology (adopted and extended from [15]).

\section{Service Perspectives}

In the following sections, we will introduce a conceptual model for services. The model does not propose a single service definition but instead suggests a number of service perspectives based on the ways resources can be used and exchanged. This approach is reflected in the model, which does not include the term "service" but instead a family of related terms, including "service resource", "service offering", and "service process". We have identified three main perspectives on services: service as a means for co-creation of value [16, 10], service as means for abstraction $[18,13,14$, $10,17]$, and service as a means for providing resource access without ownership transfer [20, 2]:

- Service as a means for co-creation of value. For most kinds of production of goods, customers are not involved. Instead, goods are produced internally at a supplier who later on sells the goods to a customer who uses them without the involvement of the supplier. In contrast, services are created and used in an interaction between supplier and customer.

- Service as a means for abstraction. Services can provide an abstraction mechanism, where resources are specified through their function and not their construction. In other words, a resource is defined in terms of the effects it has in a process, not in terms of its properties or constituents. For example, a hair dressing service can be defined in terms of the effects it has on someone's hair, not in terms of the resources being used in the execution of the service, such as scissors or electric machines.

- Service as a means for providing restricted resource access. An agent can provide access to some of her resources to another agent by transferring the ownership of 
them. However, such an ownership transfer may in some situations be undesirable or even legally impossible. Thus, there is a need for a way of offering access to resources without transferring ownership, and services provide a mechanism for this purpose. For example, instead of selling transportation vehicles, transportation services are provided.

The model, based on these three perspectives, will be presented in a series of UMLdiagrams, all of which have the REA ontology as their point of departure. Fig. 2 and 3 show services as co-creation of value, while Fig. 4 and Fig. 5 show services as abstraction mechanisms and providers of resource access without ownership transfer.

\section{Service as a Means for Co-creation}

For a typical goods producing company, its interactions with customers can be quite limited. Without any involvement of the customers, the company procures raw materials and other assets from suppliers and uses these resources to produce goods to be sold. The only role of the customer is to select which goods to purchase and pay for them. Thus, the company carries out a conversion process in isolation transforming input resources to output resources, see Fig. 2a.

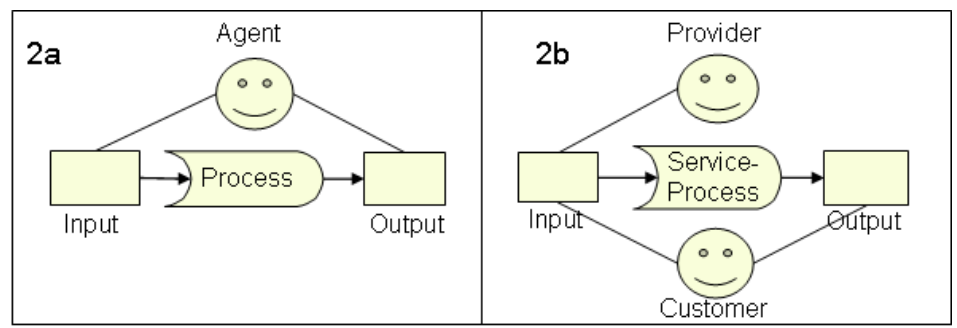

Fig. 2. Single agent process versus service-process.

In contrast, a service can never be carried out by a provider in isolation, as it always requires a customer to take part in the process. In such a service process, the provider and the customer together co-create value, as both of them provide resources to be used or consumed in the process. For example, in a photo sharing service, the service provider will supply hardware and software, while the customer will provide photos and labour. Together, they engage in a process that results in value for the customer, shareable photo albums. Pictorially, a service process can be viewed as in Fig. 2b, which shows how both a service provider and a customer jointly contribute to the service process that produces an output for the benefit of the customer.

In order to make the concept of service as co-creation more precise, it is useful to distinguish between service as a process and service as a resource. The word "service" is sometimes used to denote a process, e.g., in the phrase "Today, our company carried out 25 car repair services". In other cases, "service" is used to denote a resource, e.g., "Our company offers car repair services for the fixed price of 200 euros”. 
A service process, see Fig. 3, is a conversion process that uses or consumes resources from two agents, called provider and customer, and produces resources that are under the control of the customer. The provider in the service process has to actively participate in the process, while the customer may be passive. For example, a customer driving a borrowed car is not a service process, while a customer being driven by (a representative of) the provider is. Thus, a service process differs from other processes in three ways: First, some of the input resources are under the control of one agent, the provider, while the output resources are under the control of another agent, the customer. This means that the provider uses or consumes her resources in the service process for the benefit of another agent. Secondly, not only the provider but also the customer provides resources as input to the service process. Thirdly, the provider actively takes part in the service process.

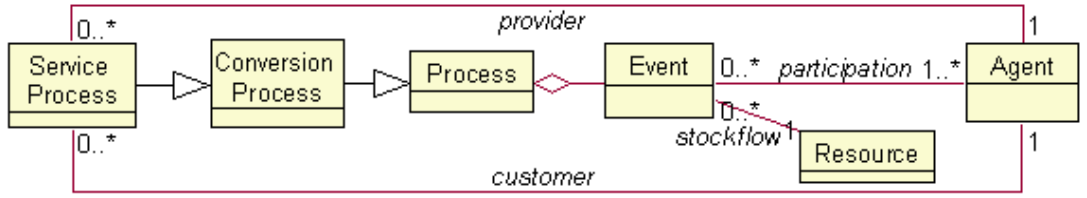

Fig. 3. REA-ontology from Fig. 1 expanded with Service Process to highlight co-creation of value between provider and customer.

\section{Service as a Means for Abstraction}

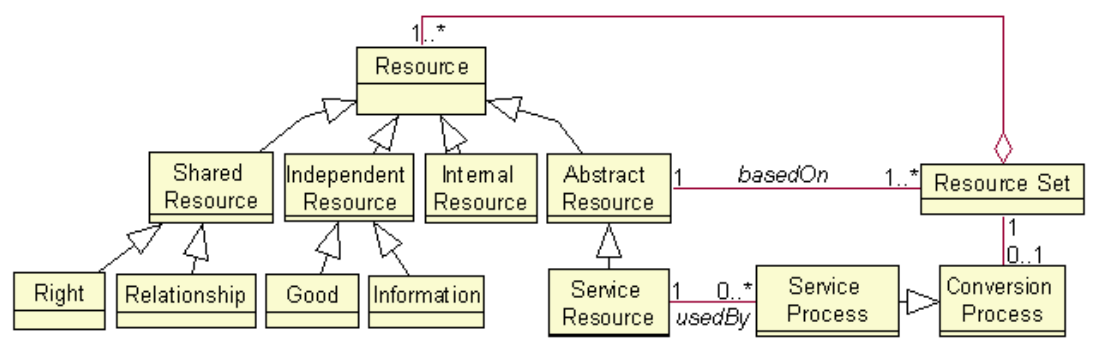

Fig. 4. Service as an abstraction mechanism.

To be able to specify resources in an abstract way provides several advantages. It becomes easier for a provider to describe the benefits of an offering when she can focus on the effects of the resource offered and abstract away from its accidental features. The provider can address the needs and wants of the customer and clarify how these are fulfilled by her offering without going into detail about its composition. Furthermore, the provider does not have to commit to any specific way of delivering her offering; instead, she can choose to allocate the resources needed in a flexible and dynamic way. 
A service resource is an abstract resource that is defined only through its use and effects in a service process, i.e. what changes it can bring to other resources when consumed in such a process. For example, a hair cut service is defined through the effects it has on the hair style of a person. It is not defined by means of the concrete resources used when cutting the hair, such as labour and scissors. Rather, the concrete resources to be used are left unspecified and can change over time. On one day the hair dresser may use scissors and on another day an electric machine, but in both cases he provides a hair cut service. Thus, the same service resource can be based on different sets of other resources, as shown in Fig. 4, and when it is consumed exactly one of these resource sets will be used.

\section{Service as a Means for Providing Restricted Resource Access}

When satisfying a need, an agent can often choose between using a service or some other kind of resource, like goods or information. Using a service instead of another kind of resource provides several benefits, as the service consumer does not own the service. This means that she does not need to take on typical ownership responsibilities, like infrastructure management, integration, and maintenance. For example, a person can satisfy her transportation needs either by buying and driving a car or by using a taxi service. In the former case, she will own the car required for the transportation, i.e. she will be responsible for cleaning it, repairing it, getting the right insurances, and many other infrastructure and maintenance tasks. When using a taxi service, on the other hand, she does not have to care about any of these responsibilities but can focus solely on how to use the taxi to best satisfy her transportation needs. Thus, services provide a convenient way of offering and accessing resources by allowing agents to use them without owning them.

Fig. 5 depicts three different ways for an Agent to make its resources available to other agents through offerings:

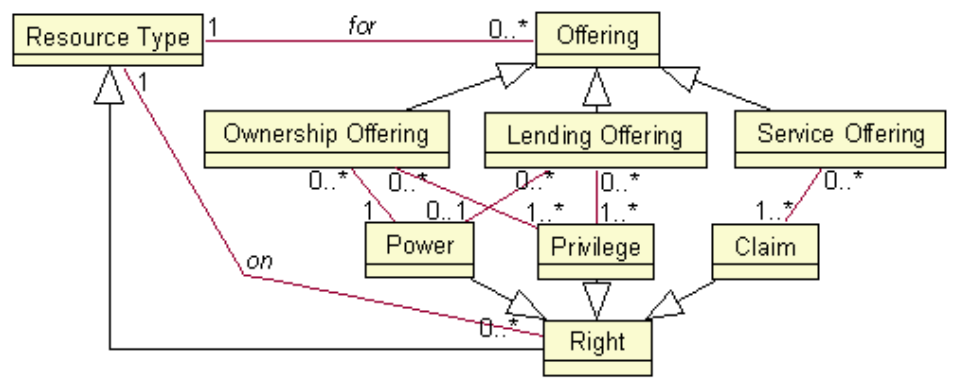

Fig. 5. Service as a means for restricted access provisioning.

- an agent may offer to sell a resource to another agent, i.e. to transfer the ownership of the resource to the other agent, as modelled by Ownership Offering. A transfer of ownership means that a number of rights are transferred from seller to buyer, in Fig. 5 modelled by class Right. The rights transferred include powers and privileges according to Hohfelds's classification of rights in section 2.4. For 
example, an agent offering to sell a book to a customer means that the agent is offering the customer privileges to use the book as well as the power to transfer the ownership of the book to yet another agent if she so wishes.

- an agent may offer to lend a resource or provide access to it in a Lending Offering. This means to offer an agent to get certain privileges on the resource for a period of time but without getting any ownership, i.e. the borrower is not granted the power to change the ownership of the resource. Optionally, the borrower may get some other powers, such as lending the resource to a third agent.

- an agent may make a Service Offering to a potential customer, which is the most abstract way of providing access to an agent's resources. A service offering means that the provider offers to use some of her service resources in a service process that will benefit the customer. Effectively, the provider restricts access to these resources. In particular, the customer is not offered any powers or privileges on any concrete resources. Instead, she is offered a claim on the provider to contribute to a certain service process.

\section{Concluding Remarks}

In this paper, we have proposed a conceptual model of the notion of service. A main characteristic of the model is that it describes services from three perspectives service as a means for co-creation of value, for abstraction, and for access restriction.

The work presented here was partly motivated by a language problem identified by Wittgenstein [19]. He contends that a word is defined by its use, that it can be used in different ways, and that there is no usage characteristic that is common for all these ways. In the context of services, this is particularly problematic since no common agreed upon definition of the term exists and the natural language terms used are often confusing. Analysing services along the dimensions co-creation, abstraction and restriction mechanisms makes it possible to distinguish between similarly labeled but different concepts. For instance, a 'health care insurance service' is different from a 'burglar insurance service' (there is little to no customer participation in the latter and hence it is not a service process).

Our three perspectives can be compared to those introduced in [1]. There the chosen perspectives are called 'service value', 'service offering', and 'service process'. The service value perspective is analogous to our abstraction perspective, where a service is described by the effects it produces, but it also contains elements from our co-production perspective. The service offering perspective is related to our view of services as a means for restricted access to resources. The service process perspective describes how a service offering is put into operation, but in contrast to our proposal the authors do not investigate realization issues in detail.

In addition to their theoretical contributions, we believe that the results of the paper will find applications in structuring service descriptions and developing service classifications. Further research will investigate these issues as well as consolidate the proposed model. 


\section{References}

1. Akkermans et al.,Value Webs: Ontology-Based Bundling of Real-World Services. IEEE Intelligent Systems, Vol. 19, No. 4, July/August (2004)

2. Bergholtz, M., Andersson, B., Johannesson, B.: Abstraction, Restriction, and Co-creation: Three Perspectives on Services. In: Advances in Conceptual Modeling - Applications and Challenges (ER 2010 Workshops), pp. 107 - 116, Springer Verlag (2010)

3. Edvardsson, B., Gustafsson, A., Roos, I. Service portraits in service research: a critical review. Int. Jour. of Service Industry Management, Vol. 16, No. 1, pp. 107-121. (2005)

4. Goldkuhl, G., Röstlinger, A.: Beyond goods and services - an elaborate product classification on pragmatic grounds, in Proc. of Quality in Services (QUIS 7), Karlstad university (2000)

5. Ferrario, R., Guarino, N., Fernandez Barrera, M.: Towards an Ontological Foundations for Services Science: the Legal Perspective. In G. Sartor, P. Casanovas, M. Biasiotti, M. Fernandez Barrera (eds.), Approaches to Legal Ontologies, Springer Verlag, (2009)

6. Fowler, M.: Analysis Patterns. Reusable Object Models, Addison-Wesley, (1997)

7. Geerts, G., McCarthy, W. E.: An Accounting Object Infrastructure For Knowledge-Based Enterprise Models, IEEE Int. Systems \& Their Applications, pp. 89-94, (1999)

8. Hohfeld, W. N.: Fundamental Legal Conceptions. Corbin (ed). Westport, Conn., Greenwood Press, (1978)

9. Hruby, P.: Model-Driven Design of Software Applications with Business Patterns, Springer Verlag ISBN: 3540301542. (2006)

10. Lusch, R. F., Vargo, S. L., Wessels, G.: Towards a conceptual foundation for service science: Contributions from service-dominant logic. IBM Systems Journal, Vol. 47, No. 1. (2008)

11. McCarthy, W. E.: The REA Accounting Model: A Generalized Framework for Accounting Systems in a Shared Data Environment., The Accounting Review (1982)

12. NESSI, http://www.nessi-europe.com

13. OASIS. Reference Model for Service Oriented Architecture 1.0, http://www.oasisopen.org/committees/download.php/19679/soa-rm-cs.pdf

14. Preist. C.: A Conceptual Architecture for Semantic Web Services. In F. van Harmelen S.A. McIlraith, D. Plexousakis (eds.), The Semantic Web ISWC 2004: Third International Semantic Web Conference, Springer, LNCS 3298, (2004)

15. REA-ontology: http://reatechnology.com/what-is-rea.html

16. Scott, E., Sampson, C., Froehle, M.: Foundation and Implications of a Proposed Unified Services Theory, in Production and Operations Management, Vol. 15, No. 2, pp. 329 - 343, (2006)

17. United Nations, Dept. of Economic and Social Affairs. Common DataBase (CDB) Data Dictionary, http://unstats.un.org/unsd/cdbmeta/gesform.asp?getitem=398 2008-02-19

18. Web Services Architecture W3C Working Group, http://www.w3.org/TR/2004/NOTE-wsarch-20040211/ (2004)

19. Wittgenstein, L.: The Blue and Brown Book, pp.1-74. New York: Harper\&Row (1980), http://www.geocities.jp/mickindex/wittgenstein/witt_blue_en.html

20. Zeithaml, V. A., Parasuraman, A., Berry, L. L.: "Problems and Strategies in Services Marketing,” Journal of Marketing 49, 33-46 (1985) 